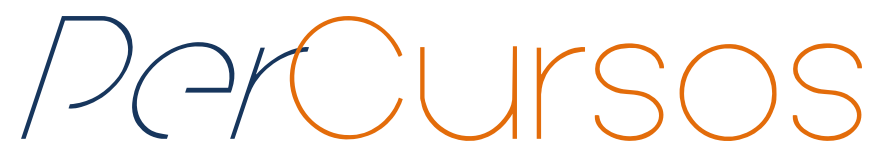

\title{
A vida como referência na educação: alguns componentes do complexo fenômeno da afetividade e das violências
}

\section{Resumo}

Este texto tem por objetivo problematizar como são constituídos alguns componentes do complexo fenômeno da afetividade. Para nos conectarmos com a vida em todas as suas dimensões, é necessário transitar em vivências pedagógicas que permitam o contato com identidade e alteridade, e nesse movimento, reconhecer-se e estrangeirizar-se no Outro, por meio do contato. É nessa perspectiva que meu olhar se dirige para os processos educacionais, com a importância de nutrir as relações por meio de uma afetividade qualificada e problematizar as violências que emergem na escola, sobretudo as violências que, em alguns casos, estão na sutileza dos gestos. Eis porque é na convivência que produzimos e reproduzimos as violências. Nesse sentido, os sujeitos envolvidos no processo não estão desvinculados de pensar, sentir e emocionar-se. A Gestão do Cuidado e a Educação Biocêntrica aparecem como uma escolha pedagógica capaz de ajudar na construção de uma escola que protege e em sintonia com o ritmo da vida.

Palavras-chave: Afetividades; Violências; Gestão do Cuidado; Educação Biocêntrica.

\author{
Sílvia Cardoso Rocha \\ Doutoranda em Educação na \\ Universidade Federal de Santa \\ Catarina - UFSC. \\ Coordenadora Pedagógica da \\ Secretaria Municipal de Educação \\ e Cultura de Jaguaruna - SC. \\ Brasil \\ silviaufsceduca@gmail.com
}

\footnotetext{
Para citar este artigo:

ROCHA, Sílvia Cardoso. A vida como referência na educação: alguns componentes do complexo fenômeno da afetividade e das violências. Revista PerCursos, Florianópolis, v. 17, n.35, p. 201 - 222, set./dez. 2016.
}

\section{DOI: $10.5965 / 1984724617352016201$}

http://dx.doi.org/10.5965/1984724617352016201 


\title{
Life as reference in education: some components of the complex phenomenon of affection and violence
}

\begin{abstract}
This paper aims to discuss how they are constituted some components of the complex phenomenon of affection. For us to connect with life in all its dimensions, it is necessary to carry over into educational experiences that allow contact with identity and otherness, and this movement, be recognized and estrangeirizar in the Other, through contact. It is in this perspective that my gaze is directed to the educational processes, the importance of nurturing relationships through a qualified affection and discuss the violence that emerge in school, especially the violence which in some cases is in the subtlety of gesture. This is why it is in the coexistence that produce and reproduce violence. In this sense, the subjects involved in the process are not disconnected from thinking, feeling and thrill yourself. The Care Management and Education Biocentric appear as a pedagogical choice able to help build a school that protects and in tune with the pace of life.
\end{abstract}

Keywords: Affection; Violence; Managed Care; Biocentric Education. 
Este texto apresenta uma reflexão a partir dos estudos realizados no Núcleo de Estudos e Pesquisas Vida e Cuidado (NUVIC) ${ }^{1}$ sobre o fenômeno da afetividade e das violências, sobretudo aquelas situadas na sutiliza dos gestos. De maneira específica, traz um recorte da pesquisa de Mestrado² apresentada em 2010 ao Programa de PósGraduação em Educação da Universidade Federal de Santa Catarina - UFSC, à Linha de Pesquisa Ensino e Formação de Educadores que teve por objetivo investigar como são constituídos os laços afetivos na relação entre educadoras e educandos, em uma escola de Educação Básica da Rede Estadual no Município de Morro da Fumaça, em Santa Catarina.

Afetividade é aqui compreendida como um estado de afinidade profunda entre as pessoas e o ambiente, capaz de originar sentimentos de amor, desvelo, amizade, altruísmo, por exemplo; ou aqueles que promovem a desqualificação dos sujeitos e limitam seu processo de humanização. Caracteriza-se como um fenômeno complexo, que não se reduz às explicações simplistas. Como um Estudo de Caso, a abordagem da pesquisa se pautou numa perspectiva etnográfica, de análise qualitativa, na qual a complexidade do olhar assumiu o diálogo com o campo empírico para construir explicações aproximadas sobre o fenômeno afetividade. A pesquisa apontou, entre outros aspectos, que a escola também reproduz as ideologias da cultura patriarcal, hierarquiza as relações, ocasiona distanciamentos entre os sujeitos, o que dificulta a tessitura de laços afetivos qualificados.

Neste percurso de estudo, algumas leituras foram importantes e busquei diálogos possíveis com autores que, fazendo uma escolha por identificação, sustentaram teoricamente a pesquisa. As opções teóricas dialogaram em torno de três conceitos: Afetividade (TORO, 1998); Relação (MATURANA, 2005) e Infância (KOHAN, 2004). Para este artigo, entretanto, optei pelo recorte que privilegia dialogar com o conceito de

\footnotetext{
${ }^{1}$ Núcleo de Estudos e Pesquisas sobre violências, vinculado ao Departamento de Estudos Especializados em Educação (EED), Centro de Ciências da Educação (CED) da Universidade Federal de Santa Catarina (UFSC) onde atuo como pesquisadora dos temas: Educação, Afetividades, Infâncias, Violências e Aprendizagens. www.vidaecuidado.ufsc.br

${ }^{2}$ Intitulada Educadoras e educandos em relação: um olhar sobre os laços afetivos na aprendizagem.
} 
afetividades destacando alguns componentes deste complexo fenômeno e sua relação com as violências.

\section{$(\mathrm{Re})$ Conhecimento e estrangeireidade: um movimento a partir do contato}

\section{com o Outro}

Com base em algumas pesquisas científicas, sabemos que a proximidade com outro ser humano nos modifica. Nossos processos internos mudam completamente com a presença de alguém, o que demonstra a sensibilidade presente no encontro com o Outro. Para Toro (2005, p. 90),

[...] a afetividade não é apenas a expressão de um sentimento individual ou uma forma sutil de comunicação, mas também a manifestação de mensagens relacionais preexistentes em todos nós que predispõem às ligações afetivas entre os seres humanos; somos de fato, unidos por múltiplos canais de conexão, dos quais não somos conscientes.

Existe um continuum afetivo entre os seres humanos, na forma de uma relação energética invisível que nos influencia. Essa hipótese de Toro (2005) inspira-se em alguns estudos científicos, como o diálogo psicotônico com Julius Fast, o qual demonstrou, colocando sensores de tensão muscular no corpo de duas pessoas, que a simples proximidade entre elas mudava os níveis de tensão. Isso significa que cada um tem, em relação ao outro, um efeito relaxante ou tensivo. A partir de 1970, com a publicação do livro de Julius Fast, sobre a Linguagem do Corpo, foi possível reacender algumas reflexões do trabalho de Charles Darwin publicado em 1872 intitulado: A expressão das emoções no homem e nos animais.

Há, também, diversos estudos sobre a carícia e sobre como ela afeta os seres vivos. Os estudos tomográficos realizados com casais durante um beijo ou no decorrer do ato sexual evidenciam mudanças em todos os níveis neurofisiológicos: "alteração do equilíbrio neurovegetativo, dos níveis de secreção endócrina e da ação de 
neurotransmissores, com modificações do metabolismo celular e repercussões na defesa imunológica" (TORO, 2005, p. 90). A opinião de lbor (1952) ${ }^{3}$ vai mais longe, quando afirma que pessoas "instalam-se” nos nossos órgãos. Baseado em sua experiência clínica em psicopatologia, adverte sobre a influência recíproca que as pessoas exercem entre si, alterando funções orgânicas específicas. As pessoas, energeticamente se "alojam" nas artérias, no coração, no aparelho digestivo ou nos genitais, contribuindo assim para alterar o funcionamento desses órgãos. Essas pesquisas sugerem que "a percepção do outro provoca respostas que abraçam a totalidade do organismo, e não só as emoções, concluindo que os seres humanos são órgãos receptores e emissores de afetividade" (SOUSA, 2002, p. 21).

Rolando Toro (1998, p. 08, tradução nossa) alerta que "o conceito de afetividade é complexo, mas os fatores estruturais que o determinam podem ser claramente definidos: identidade, nível de consciência, nível de comunicação, ecofatores e antecedentes biográficos". Esses componentes estruturais da afetividade são fundamentais na apropriação desse complexo fenômeno. Ela está profundamente ligada à identidade de cada indivíduo, e para o autor, os indivíduos que possuem uma identidade "alterada" não conseguem identificar-se com o Outro. Seu comportamento é intolerante, destrutivo e defensivo, movimentos que regem as condutas de racistas, mafiosos e governos totalitários, para ilustrar.

Precária consciência de si pode acarretar transtornos de autoestima, sentimentos de inferioridade ou superioridade que impedem expressões da afetividade, tais como o amor, a amizade, o altruísmo. Nesse cenário, para nos conectarmos com a vida em todas as suas dimensões, é necessário transitar em vivências pedagógicas que permitam o contato com identidade e alteridade, e nesse movimento, reconhecer-se e estrangeirizarse no Outro, por meio do contato.

A sensação intensa e comovente de estar vivo, gerada pela unidade orgânica, constituiria a experiência primordial da identidade, e seria

\footnotetext{
${ }^{3}$ Psiquiatra espanhol; professor Catedrático da Universidade de Madri.
} 
constantemente influenciada pelo humor endógeno e pela estimulação externa, por ter origem visceral. (TORO, 2005, p. 100)

Para Toro (1998, p. 08, tradução nossa), “a percepção do essencial e o nível de expansão da consciência vinculam o indivíduo em forma orgânica ao universo e aos outros seres humanos". O que permite ao indivíduo exaltar a gratidão pelo fato de existir e desenvolver sentimentos de amor, de aceitação e de compaixão.

A comunicação através da linguagem geralmente engendra um significado preciso, contudo ela adquire novos significados com o tom da voz, ritmo e com o comportamento afetivo. Podemos nos comunicar de maneira sutil, por gestos e algumas vezes até em silêncio, já que o silêncio não é necessariamente o fim do diálogo, mas sim, entre outras possibilidades, uma das maneiras que utilizamos para negar a presença do Outro, recusar sua e nossa presença, para não produzir o encontro, desqualificar a continuidade da palavra dita, com o que é dito sem dizer. Sabemos que o corpo também "fala". O olhar, em algumas situações, diz mais que as palavras; é necessário sensibilidade para essa leitura. Existem "patologias"4 da linguagem gestual e corpórea que se caracterizam pelas inúmeras formas com que nos apresentamos e somos apresentados às afetividades, e que podem ser vistas como dificuldades em se expressar, com as quais estamos habituados. Enraizamo-nos em modos de cultura que se evidenciam pelo individualismo e nos ensinam a manter certa distância do Outro. Diferentes "patologias" na convivência podem ser notadas em algumas pessoas, que continuamente desqualificam outros humanos, aqueles mais próximos e os que se encontram em longínquos lugares. Essa conduta cria um "vício", na maioria das vezes, inconsciente e mascarado como "crítica construtiva”, em geral acompanhada de uma gentil qualificação.

As potencialidades de todos os indivíduos podem ser bloqueadas ou estimuladas pela qualidade afetiva do contato com o ambiente.

\footnotetext{
${ }^{4}$ Rolando Toro usa este termo "emprestado" da Medicina para explicar as condutas que desqualificam o Outro na convivência.
} 
A afetividade, portanto, está determinada pelos fatores genéticos, fisiológicos, culturais e ambientais. Somente o estado de expansão da consciência pode regular as relações humanas, e transcender a malignidade que adquire formas monstruosas no inconsciente coletivo. (TORO, 1998, p. 11, tradução nossa)

É nessa perspectiva que meu olhar se dirige para os processos educacionais, com a importância de nutrir as relações por meio de uma afetividade qualificada. A proximidade corporal entre nós abarca o movimento de amor de um indivíduo para o Outro, e este é da mesma natureza do infinito movimento da energia cósmica que luta para se expressar em nossas vidas, desesperadas em meio às formas culturais inadequadas como as guerras, as competições e a negação das expressões de sentimentos e emoções que dirigem nossas relações. O que pode ser também refletido com as palavras de Sousa (2002, p. 61):

[...] todas as atividades que orientamos estão situadas numa concepção de mundo que contém uma abordagem pedagógica. Então, há também uma pedagogia que vai saciar a sede dos educandos e esta vai estar assentada no reconhecimento ou na negação um do outro. Toda ação educativa incorpora os gestos, as escolhas de toda ordem, as participações associativas, o modo como o trabalho é dividido entre a comunidade, as pequenas socialidades de vizinhanças, os olhares de limite e de permissão para a aproximação corporal, os desejos que pulsam no movimento do grupo, suas crenças, porque considera tudo isso imerso num ambiente afetuoso, emocional, que não se aprende fora de uma razão sensível.

Com esta perspectiva, podemos pensar uma nova pedagogia que considere que é o afeto que nos dá alegria de viver, a sensação de nos sentirmos vivos, ligados à natureza e aos outros seres humanos, que resgata "a selva interior", numa contínua exaltação da vida.

O contato com este distanciamento da sacralidade da vida na história da humanidade pode ser evidenciado ao longo do processo civilizatório, quando a moral foi evidenciada em detrimento de questões consideradas vitais, como o instinto, por exemplo, que foi relegado ao plano de uma estrutura desagregadora da cultura e 
sinônimo de selvageria. Mas, por mais bloqueados que estejam os instintos vitais, eles anseiam sempre por liberdade, carregam as forças originárias da vida. Para Rolando Toro (2005), o Princípio Biocêntrico tem como referência imediata a vida, inspira-se nas leis universais que conservam os sistemas vivos e que tornam possível sua evolução; estabelece um modo de sentir e de pensar que toma como referência existencial a vivência, como

[...] percepção intensa e apaixonada de estar vivo, aqui e agora; como a intuição do instante de vida capaz de estremecer, harmoniosamente, o sistema vivente humano. A vivência também pode ser entendida como uma experiência vivida com grande intensidade por um indivíduo, no momento presente, o que envolve a cenestesia ${ }^{5}$, as funções viscerais e emocionais. (TORO, 2005, p. 30)

Uma razão sensível atrelada à nossa biologia, tornando-nos seres predispostos ao contato e ao acolhimento. Essa capacidade foi encolhida porque nos humanizamos com as ferramentas predominantes de uma cultura predatória, com relações tecidas na desconfiança e na competição, sem considerar o Outro. Consequentemente estamos imersos, ainda no início do século XXI, em dores e sofrimentos de toda ordem.

O Princípio Biocêntrico pode delinear uma educação com enfoque na vida instintiva e na construção do conhecimento biológico e social. Para isso, Toro formulou pressupostos para uma Educação Biocêntrica, cujos ensinamentos e relações estão centrados no reconhecimento da sacralidade da vida e tendo a Biodanza ${ }^{6}{ }^{6}$ como mediadora, para promover a reeducação afetiva dos indivíduos e conservar sua diferenciação. Uma proposição educativa crítica, formuladora de conhecimentos pertinentes com a disposição de cuidado ${ }^{7}$ e autoestima. Formação que leva em conta a

\footnotetext{
${ }^{5}$ Impressão geral de bem ou mal-estar, resultante de um conjunto de sensações internas, ou ainda, capacidade intensa de sentir prazer.

${ }^{6}$ De acordo com Toro, Biodanza é um sistema de integração humana, de renovação da vitalidade e de reeducação afetiva.

7 Cuidado é aqui entendido no sentido de cura a que Heidegger (2005) se refere, numa perspectiva de antecipar-se ao bem estar da vida, o que só acontece em relações de reciprocidade, de mútuo cuidado.
} 
consciência e a vivência para os aprendizes redescobrirem que "a sua expressão exige uma ação no mundo através do diálogo com o Outro, para uma transformação da realidade individual e social" (CAVALCANTE, 2007, p. 8).

Gonsalves (2009, p. 09) afirma que a teoria da Educação Biocêntrica toca "no sagrado que existe em cada um de nós. Ao fortalecer os laços de afetividade entre as pessoas, práticas educativas biocêntricas lançam as sementes de uma sociedade do cuidado". É bastante audacioso acreditar que mudanças são possíveis, mas toda realização grande ou pequena nasce de sonhos transformados em atitudes, sonhos que às vezes nascem sozinhos, mas que ao contagiar a coletividade podem se traduzir em sementes plantadas para que sejam regadas, com cuidado, por quem desejar.

\title{
O Cuidado: nutrição afetiva para o bem-estar do Outro
}

\begin{abstract}
Dependemos afetivamente dos outros, tanto quanto dependemos do ar, da água ou da luz, da mesma maneira que os seres de um ecossistema têm necessidade uns dos outros para assegurar sua integridade biológica. (RESTREPO, 2001, p. 75)
\end{abstract}

Somos seres em relações de interdependência, portanto, não vivemos sozinhos. Tornamo-nos o que somos emaranhados nos processos de convivência com tudo o que existe e vive ao nosso redor, e isso inclui os organismos vivos, as coisas e o próprio Universo. Nesse processo de convivência, promovemos o cuidado e a ajuda mútua que desperta em nós sentimentos de benevolência. Cuidar deixa-nos resgatar o que há de melhor em nós, pelo fato de reacender a nossa humanidade em trajeto. Nesse sentido,

[...] toda forma de crueldade, de perversão praticada contra as pessoas e outros seres vivos nos afeta, marca em nossa pele inscrições de dor e sofrimento social, mesmo quando não percebemos individualmente, pois ninguém pode manter-se imune ou indiferente para sempre. (SOUSA, 2010, p. 11) 
De acordo com Boff (2013), o cuidado vincula-se ao interesse em construir um mundo aperfeiçoado por laços afetivos. Laços que tornam as pessoas e as situações preciosas, mensageiras de valor, dedicação e responsabilidade existencial. E a escola pode ser pensada como um lugar do cuidado, o que nos convida a ousar com práticas educativas que promovam atitudes de aconchego, de respeito ao Outro na sua subjetividade, para abandonar as atitudes competitivas.

Quando falamos do cuidado como pressuposto da gestão, na ótica dos contextos educativos, precisamos levar em consideração a disposição ético-estética-afectiva da convivência que reconhece o outro como possibilidade, sobretudo, o que ele me diz. (SOUSA, 2010, p. 13)

A alteridade, ou aquilo que a presença do Outro, em convivência, altera em mim, começa a ser observada sob a estética do sentir em comum. O ato de reconhecer-se no Outro é por excelência um ato de sabedoria, que exige uma constante autoética que pode ser ensinada e aprendida afetivamente. O cuidado se configura como gestos concretos e se expressa no movimento de congruência. Conforme Maturana (1999, p. 124), “[...] a congruência dinâmica da estrutura dos sistemas vivos com suas circunstâncias é o resultado de uma história de mudanças estruturais coerentes dos sistemas vivos e do meio no qual eles existem". Ao situar o plano relacional dos sujeitos envolvidos no processo de ensinar-aprender dentro de uma instituição de ensino, não se pode deixar de lado as questões culturais que moldam as atitudes destes sujeitos.

Culturalmente fomos educados para correr em busca de méritos profissionais dados pela ideologia das competências, o que pouco se reflete sobre os valores vinculados à solidariedade, generosidade e compaixão. No conhecimento de que "não há uma realidade exterior a nós e que os conteúdos escolares precisam ser experimentados e construídos com nossos pares, os valores de convivência aparecem" (MATURANA, 2005, p. 13). Não sabemos lidar com eles por medo de perder a nossa autoridade frente àqueles que educamos. 
Por que a convivência entre as pessoas da escola ainda é pouco respaldada por atitudes de autorrespeito e de respeito pelo Outro? O que as impede de ouvir e olhar amorosamente, de falar com delicadeza quando se dirigem aos colegas ou aos educandos? Como se empenham para validar o que o Outro sente, pensa, com seus desejos e necessidades? É possível criar situações calorosas, nas quais os abraços façam parte das rotinas escolares? Por que, quando falamos de afetividade, lhe atribuímos um tom pejorativo ou meramente romântico? Questões que nos incitam a perguntar: o que pode e o que pede o corpo nosso nesse espaço? Nas palavras de Restrepo (2001, p.105), "a ternura, a dependência, a gratuidade e a busca da singularidade são experiências que só podem acontecer na geografia do corpo". Então, vamos instalar nosso corpo sensorial na escola, alimentar suas necessidades orgânicas, inclusive com afetos de bem querer.

Eis porque é na convivência que produzimos e reproduzimos as violências. De acordo com Sousa (2002, p. 30), "violências são todo e qualquer processo que produz a desorganização emocional do sujeito, a partir de situações em que este é submetido ao domínio e controle de um Outro". Enquanto práticas multifacetadas, escancaradas e/ou camufladas, as violências afetam nossa corporeidade. Com destaque para o pouco que pode se dizer da corporeidade na escola, já que ali o corpo precisa ser disciplinado e suas formas devem ser retas. Uma corporeidade que dança pouco, que evita olhar nos olhos. Esquecida e reprimida como potência da vida.

Somos seres multidimensionais e nos sentimos harmonizados se nossas ações, nossas emoções, afetos, vontade, pensamentos, imagens, autopercepção, o ambiente e os níveis energéticos mais sutis estiverem em equilíbrio. O corpo é a expressão-síntese de todas essas dimensões. (CELANO, 1999, p. 43)

Sabemos que tudo o que é físico é, na realidade, também energético. O corpo interage com outros corpos e com as vibrações do Universo. Cuidar da harmonia dessa energia pressupõe entender que como sistemas vivos, nós humanos existimos em três campos: como fisiologia, como relação e como linguagem. Na fisiologia está inscrita a nossa estrutura e a nossa organização como sistema vivo. Embora todo sistema vivo 
carregue uma estrutura advinda da herança filogenética, as interações com o meio promovem as alterações que são provenientes do processo de autopoiese ${ }^{8}$. Assim, quando as circunstâncias do meio provocam alterações estruturais que não satisfazem as necessidades do ser vivo, ou que não são próprias deste, sua organização é afetada.

Como sistemas moleculares, os sistemas vivos são abertos aos fluxos de matéria e energia. Enquanto sistemas autopoiéticos, sistemas vivos são sistemas fechados em sua dinâmica de estados, no sentido que eles são vivos apenas quando todas as suas mudanças estruturais forem mudanças estruturais que conservam sua autopoiese. (MATURANA, 2006, p. 175)

Esse conceito trazido por Maturana e Varela me suscita a visualizar as relações entre professores e estudantes, considerando a emergência de cuidar da qualidade das relações em sala de aula, mais especificamente nas Séries Iniciais do Ensino Fundamental, lugar em que estão as crianças com suas infâncias, estas compreendidas como plurais. Infâncias que não se apresentam da mesma forma, não vivem as mesmas histórias, não provêm dos mesmos arranjos familiares, não desfrutam dos mesmos cuidados, não habitam as mesmas ausências. No reconhecimento da pluralidade de suas travessias, as subjetividades encontram acolhimento. A qualidade das relações, desse modo, contribui para a conservação da organização viva destes sujeitos, ou para a sua desestruturação.

Maturana (2006, p. 177) ainda alerta para o viver humano, que segundo o autor só ocorre em relação. Mas, o que acontece nesta relação tem expressão na corporeidade; e o que acontece nesta, incide na relação. Como humanos, nossa existência se dá no

\footnotetext{
${ }^{8}$ Autopoiese ou autopoiesis (do grego auto "próprio", poiesis "criação") é um termo cunhado na década de 70 pelos biólogos e filósofos chilenos Francisco Varela e Humberto Maturana para designar a capacidade dos seres vivos de produzirem a si próprios. Segundo esta teoria, um ser vivo é um sistema autopoiético, caracterizado como uma rede fechada de produções moleculares (processos), onde as moléculas produzidas geram com suas interações a mesma rede de moléculas que as produziu. A conservação da autopoiese e da adaptação de um ser vivo ao seu meio são condições sistêmicas para a vida. Portanto, um sistema vivo, como sistema autônomo, está constantemente se autoproduzindo, autorregulando, e sempre mantendo interações com o meio, e este apenas desencadeia no ser vivo mudanças determinadas em sua própria estrutura, e não por um agente externo. Disponível em: <http://pt.wikipedia.org/wiki/Autopoiese>. Acesso em: 10 de setembro de 2015.
} 
domínio de nossas interações e relações, ou seja, no campo de nosso agir no mundo, pois são estas interações do organismo que modulam a sua fisiologia. A linguagem adquire aqui um papel relevante. Em suas pesquisas, Maturana (2005, p. 19) defende que "o peculiar do humano não está na manipulação, mas na linguagem e no seu entrelaçamento com o emocionar".

De acordo com Toro (1998, p. 09), a cultura do consumo gerou uma "patologia da comunicação gestual", que se caracteriza pela dificuldade que as pessoas têm para se aproximar do Outro. Gestos como o abraço, o beijo, o reconhecimento da fala, daquilo que o Outro revela com o olhar foi desvalorizado culturalmente. Os seres humanos, antes de iniciar um diálogo, criam gestualmente, um contexto de comunicação.

Então, a linguagem dos gestos publica o nível de receptividade e afetividade dos sujeitos em interação. Na convivência sensual, em que a linguagem ganha o sentido primordial, todo estilo de comunicação pode ser acolhido ou refutado. Para Sousa (2002, p. 118),

[...] a linguagem atravessa o ser e o estar em relação, edifica um social de reciprocidade e cria uma estética da convivência com espaços de cuidado do outro. Associa, de maneira fecunda, as disposições individuais e suas ambivalências; conjuga alteridade e pluralidade na comovedora ousadia que move nossa aventura como sistema vivo.

O que pressupõe o cuidado com o Outro? É possível cuidar do Outro sem cuidar de si mesmo? Desejamos conhecer e ousar apostar em uma educação pautada no movimento de encontro com a vida, que tenha como fundamento ético-estético das relações, a Gestão do Cuidado? O que define a Gestão do Cuidado?

Uma modalidade de Gestão e de Cuidado que respeita as especificidades inerentes aos organismos vivos, tais como o ritmo, o ímpeto, as emoções e os sentimentos endógenos (interno ao organismo; o que é próprio de nossa natureza como organismo vivo), que reconhece as instituições, e de maneira singular a escola, como lugar social do cuidado, para 
assegurar a cada criatura humana o pleno desenvolvimento e a sua integridade. (SOUSA, 2010, p. 13)

Sustentar, teórica e metodologicamente uma Gestão do Cuidado na escola demanda proporcionar aos seus profissionais uma formação ética, com uma estética biocêntrica, pois de acordo com Maturana (2005, p. 30), o modo como vivemos forja o estilo de como educamos. Sistematicamente, a formação inicial e continuada tem ignorado essa premissa para o desenvolvimento pessoal e profissional. Como pode um educador ensinar o cuidado, a democracia, a ética, por exemplo, se ele não vivencia tais princípios? Ampliar o conhecimento e a problematização acerca da construção de uma Escola que Protege ${ }^{9}$ crianças e adolescentes em contextos de violências sugere compreender alguns aspectos epistemológicos que orientam a Gestão do Cuidado:

1) O reconhecimento da sacralidade da vida: imbuídos desta concepção, todas as formas de vida são reconhecidas como sagradas; acredita-se na configuração da vida como uma rede de interdependência; a prioridade da vida é absoluta.

2) O amor funda o social: Para Maturana (2005), “o amor é a emoção que funda o social ou, a aceitação do outro como legítimo outro na convivência". Sugere reconhecer a legitimidade da criança em seu contexto; pautado nesse (re) conhecimento abre-se a escuta às vozes da criança, legitimando sua presença e palavra. Assim, percebese que cada criança é única e as políticas de atenção não podem estar encarceradas em padrões que inviabilizam esta distinção.

3) Corpo e espírito como unidade indissociável: A Gestão do Cuidado não opera pela lógica binária de causa e efeito ou lógica disjuntiva. Mas sim pela conectividade. O que pressupõe a unidade entre corpo e espírito; a partir de um olhar sistêmico, no qual as partes compõem o todo, que só pode ser compreendido a partir das partes.

\footnotetext{
${ }^{9}$ Destaco aqui o Curso de Especialização a Gestão do Cuidado: Escola que Protege, desenvolvido nos anos 2010 e 2011 pelo Núcleo de Pesquisas Vida e Cuidado - NUVIC, vinculado a Universidade Federal de Santa Catarina- UFSC, do qual faço parte como pesquisadora. Este curso de especialização problematizou junto aos profissionais da educação, os pressupostos teóricos e metodológicos que orientam a Gestão do Cuidado, para construir uma Escola que Protege.
} 
4) Ensinar pela vivência: nesta concepção, a vivência antecede a consciência, e é no modo-de-ser-afetivo que tecemos nossos saberes. Tornamo-nos o que somos na comvivência, em presença.

5) A recusa de toda forma de sofrimento: o que significa não aceitar qualquer abuso nas relações, recusar a guerra da verdade, o belicismo da comunicação verbal, a necessidade de ser aprovado (a); Cuidado é aqui entendido no sentido de cura ou, nutrição afetiva para o bem-estar do outro, amparado na perspectiva de Heidegger (2005); Desse modo é possível evitar processos geradores de outras violências.

6) Criar contextos de intercomunicação: pautado numa ética relacional, criar ambientes que favoreçam uma pedagogia do cuidado e proteção, sustentada na responsabilidade social, e no estímulo da palavra livre.

7) A convivência é centralidade na gestão: nas relações de convivência, contribuir com atitudes que qualificam as relações e o ser de cada um.

8) Aperfeiçoar nosso processo de humanização: olhar o Outro e a nós mesmos com sensibilidade para experimentar a autoaceitação e o autorrespeito, "ajudar o outro a existir no amor" (SOUSA, 2011).

\section{Evidências: a afetividade na perspectiva das educadoras}

Nas minhas idas à escola, campo de pesquisa, em determinado momento convidei as professoras participantes ${ }^{10}$ às Rodas de Conversa. Foram realizados seis encontros, em que além das discussões acerca do tema da afetividade, explicitadas através de depoimentos, as professoras resgataram aspectos de suas histórias de vida, situados tanto no campo pessoal, quanto profissional. Por que caracterizei estes encontros na forma de roda?

Roda - relembro aqui como símbolo: roda, Mandala, caracol, labirinto, bolha, túnel, círculo, movimento. Símbolo trazido por pesquisadores da interdisciplinaridade e nos registros das antigas civilizações. Proposto nesta pesquisa como um movimento de encontro com o Outro na construção do conhecimento. Não de um conhecimento

\footnotetext{
${ }^{10}$ Participaram da pesquisa três educadoras dos Anos Iniciais do Ensino Fundamental.
} 
qualquer, mas daquele que nasce da dúvida, do questionamento e da constante recursividade.

A pesquisa apontou, entre outros aspectos, que a escola também reproduz as ideologias da cultura patriarcal, hierarquiza as relações, ocasiona distanciamentos entre os sujeitos, o que dificulta a tessitura de laços afetivos qualificados.

Na escola, a afetividade é considerada nos discursos dos educadores como tema relevante. No entanto, ao olhar a dinâmica que entrelaça o aprender e o ensinar, ao considerar como pressuposto a afirmação da centralidade do conviver no processo educativo, o qual tem como base a análise dos laços de afetividade que são construídos pelos sujeitos envolvidos nesta relação, é possível dizer que não existe um interesse, por parte dos educadores, pelo modo como seus gestos afetam os educandos. Talvez porque desconheçam como afetam e são afetados no interstício das relações interpessoais.

O conceito de afetividade é assimilado pelos educadores de forma limitada, quase sempre como troca de carinho. Pautada na ideologia das competências, a práxis pedagógica oportuniza raras atitudes de solidariedade com o Outro, portanto, o encontro é tecido, na maioria das vezes, por afetos cujas características são pouco qualificadas. Na dinâmica desse processo, crianças e adultos esforçam-se para atender às expectativas da instituição e criam comportamentos automatizados, autorizados pelas normatividades e voltados para um fim a ser alcançado, o que previne ante o viver "aqui e agora".

Durante uma Roda de Conversa provoquei as educadoras a responderem como o afeto é demonstrado na sala de aula:

Depende da situação. Eu demonstro (gagueja), (pausa); vai muito do teu dia, depende do teu dia, se tu acordaste bem, se aquela turma está te trazendo naquele momento uma energia positiva, aí tu transmites também uma energia positiva; se os alunos estão calmos naquele dia, se a atividade que eu estou dando foi mais agitada ou os deixou mais calmos. Tudo isso eu demonstro, eles demonstram através da relação, ao observar mais profundamente o aluno, aquele novo olhar, porque às vezes tu tens que parar, né? Muitas vezes tu estás ali atrelada ao 
conteúdo, envolvida no conteúdo e depois tu para e pensa: mas aquele aluno está diferente, e aí a gente procura saber o por que. Deu? (Informação verbal) ${ }^{11}$

Sua fala expõe algumas situações da sala de aula que são permeadas por momentos tranquilos e outros mais agitados. O "clima" neste recinto depende das interações do grupo, em que acontecem as trocas que ela nomeia como "energia". São os fios que tecem as relações, talvez amparados em sentimentos que facultam o reconhecimento do Outro na relação. Evidencia ainda a preocupação com o conteúdo, como algo que absorve sua vitalidade e que demanda "parar" para pensar no que acontece com o aluno; constata que essa parada exige um novo olhar, um esforço para adotar as precisões e interesses do estudante naquele momento. É evidente o desconforto em declarar seu significado à palavra afeto, quando a professora pergunta: deu?

Isso evidencia também que os conteúdos escolares ocupam o tempo do estarjunto e a preocupação das educadoras. Ensinar é apreendido como atitude de repassar os conteúdos contidos em uma grade rígida e desconectada da realidade dos educandos. Dessa maneira, o maior desafio das professoras é descobrir maneiras outras de motivar os estudantes, especialmente os que apresentam as construídas dificuldades de aprendizagem.

O distanciamento corporal exigido entre educadores e educandos é evidenciado desde a arquitetura escolar, o que inclui a sala de aula, que instala as professoras à frente dos estudantes. A falta de liberdade para os movimentos corporais das crianças cria aprisionamentos nas carteiras, o que é agravado pela exigência de cumprir as normas, pela ordem para que "fiquem quietos", sem deixar transparecer sentimentos e emoções. É a lógica do dever-ser que rege a vida: não deve conversar, não deve tocar o Outro, não

\footnotetext{
${ }^{11}$ Entrevista concedida por Esperança (nome fictício escolhido pela participante) durante Roda de Conversa realizada em 14 de julho de 2010. Morro da Fumaça, 2010. 1 arquivo .mp3 (60 min.). A entrevista na íntegra encontra-se transcrita na Dissertação de Mestrado mencionada neste artigo e intitulada Educadoras e educandos em relação: um olhar sobre os laços afetivos na aprendizagem.
} 
deve ser um sujeito. Para transgredir essas normas os educandos se tocam, mas em geral de maneira violenta, confundindo a carícia com o agarrar.

Para os participantes da pesquisa, a escola é o lugar da produção do conhecimento formal, apenas volvido para a capacitação, para o trabalho, desvinculado da formação humana, aquela que reconhece o Outro como legítimo outro na convivência. Esse olhar inviabiliza a criação pedagógica de momentos e espaços apropriados ao estabelecimento de interações sociais, capazes de promover o desenvolvimento do sujeito em todas as suas dimensões, ungido por uma afetividade qualificada.

É possível assegurar, então, que a maneira como estes sujeitos se relacionam distingue os laços afetivos. Nessas relações há um esforço por parte das educadoras em não expressar sua afetividade, dado que as emoções são controladas e que a afetividade é confundida com ameaça a sua autoridade, ou “falta de domínio de classe”. Ou seja, laços tecidos de maneira frouxa podem deixar transparecer intimidades, então, é mais adequado não abrir espaços para o vínculo que afeta a relação indissociável entre ensinar e aprender, ainda que essa postura retarde o encanto dos estudantes com o conhecimento escolar.

A educação transmitida pela escola não está atenta aos artefatos que produzem o atrofiamento da inteligência afetiva, aos "antolhos" que limitam uma visão do mundo guiada pelo cuidado. Educadoras e educandos não se sentem satisfeitos com o ambiente profissional em que atuam e estudam.

Os desígnios da educação raramente são mediados pelo movimento de encontro com a vida, que tenha como fundamento ético-estético as relações com a Gestão do Cuidado. No entanto, participantes da pesquisa expõem uma disposição afetiva para cocriar os processos de vivência e com-vivência, desde que este espaço lhes seja oportunizado na organização escolar.

A infância é concebida como uma temporalidade etária e linear vivida pela criança. Como uma fase de potencialidades, mas como possibilidade de vir a ser. Antagonicamente, essa potencialidade descaracteriza a criança e a transforma em tábula rasa, passível de ser moldada. Anula o que ela tem de espontaneidade e criatividade. Sua 
experiência na escola é marcada pelas normas e pelo poder disciplinar, o que favorece para conduzir as crianças numa mesma direção, precisa, sem levar em conta as singularidades. São vistas, ao mesmo tempo, como adultos em miniatura, que precisam de proteção no sentido da vigilância. Nessa rede, a escola ainda carece de uma compreensão afetiva do conceito de infância, e enquanto este não é aclarado no contexto curricular, a escola segue com práticas que adulteram a infância e sedimentam os processos adultocêntricos.

Estas evidências nos levam a problematizar caminhos na construção de uma escola que alcance o humano que nos habita em processo como um ser emocional desde a sua biologia, como sujeito capaz de aprender de forma prazerosa, como alguém que, além da capacitação, demanda formação humana para poder crescer com responsabilidade social, também exige um aprofundamento teórico, uma compreensão metodológica e uma unidade reflexiva que possa entrelaçar as diferentes dimensões afetivas que nos compõem. Ainda que a cultura ocidental tente negar o valor do afeto nas relações e o sistema escolar se esforce para ilustrar esse ditame, uma e outra não conseguem paralisar os movimentos de vida presentes nos espaços de convivência, onde as experiências abarcam os sujeitos e as vozes anunciam rituais de canto que não conseguem calar.

Foi possível observar que as expressões de vida desafiam os ditames culturais. A vitalidade das crianças salta aos olhos nesse ambiente, por meio de suas atitudes, com o coração acelerado porque correm pelo pátio ao encontro do Outro, abraçam os colegas, beijam, brincam com a sabedoria interna de que o tempo e o controle lhes escapam, ávidos para que não asfixiem o prazer da convivência. Estar com seus pares é para essas crianças motivo de júbilo, mas quando chegam à sala de aula, cada um se dirige para sua carteira, em silêncio, ouvindo a palavra professoral. Neste cenário, o distanciamento é evidente, o movimento corporal é restrito, já que precisam ficar sentados nas cadeiras em frente às carteiras e enfileirados. Paradoxalmente, nesse mesmo ambiente estão professores que expressam sua criatividade e colocam a poesia a favor da liberdade artística. 
Algumas perspectivas que podem orientar as ações pedagógicas: as atividades escolares, pelo exposto, não podem reivindicar neutralidade. Elas inscrevem significações que se derramam por toda a multidimensionalidade do humano, criam paisagens de esperança e de desalento, encorajam e amedrontam, propiciam sucessos e fracassos, enaltecem e humilham. Nada é trivial quando se trata de ações humanas, agimos guiados por nossa inteligência e nossas maneiras afetam. Assim, podemos desejar uma escola que incentive a arte de ser-junto, com poesia e musicalidade, com uma razão sensível para fortalecer a convicção de que é possível ser feliz, também na escola.

Acredito que a escola, embora reproduza os paradigmas de uma cultura tanática que imprime rituais de sacrifício e desprazer à aprendizagem é, paradoxalmente, um lugar onde a vida ganha potencialidades. Essas potencialidades estão nos sujeitos, pois são eles os coautores dos enredos que inauguram suas histórias de vida, com desdobramentos também no cotidiano escolar. Para mim, esta constatação aponta que os professores, quando podem acessar a uma formação que oportuniza a aprendizagem da Gestão do Cuidado, guiam seus olhares para a infância como devir, no presente da convivência, "aqui e agora”. E isso poderá fazer da escola um lugar de relações afetivas, em que cuidar mutuamente torna-se o destino pedagógico.

\section{Referências}

BOFF, Leonardo. Saber cuidar: ética do humano. Petrópolis, RJ: Vozes, 2013.

CELANO, Sandra. Corpo e mente em educação: uma saída de emergência. Petrópolis: Vozes, 1999.

GONSALVES, Elisa Pereira. Educação biocêntrica: o presente de Rolando Toro para o pensamento pedagógico. João Pessoa: Editora Universitária - UFPB, 2009.

HEIDEGGER, Martin. Ser e tempo. São Paulo: Vozes; Universidade São Francisco, 2005.

CAVALCANTE, Ruth et al. Educação biocêntrica: um movimento de construção dialógica. 4 ed. Fortaleza: Edições CDH, 2007. 
IBOR, Juan José López. El descubrimiento de la intimidad y otros ensayos. Madri: Aguilar S.A. de Ediciones, 1952.

KOHAN, Walter Omar (Org.). Lugares da infância: filosofia. Rio de Janeiro: DO\&A, 2004. MATURANA, Humberto. Cognição, ciência e vida cotidiana. Belo Horizonte: UFMG, 2006. MATURANA, Humberto. Emoções e linguagem na educação e na política. $4^{\mathrm{a}}$ ed. Belo Horizonte: UFMG, 2005.

MATURANA, Humberto; REZEPKA, Sima Nisis de. Formação humana e capacitação. 4. ed. Petrópolis: Vozes, 2003.

MATURANA, Humberto. Transdisciplinaridade e cognição. In: CETRANS. Educação e transdisciplinaridade. São Paulo: TRIOM, 1999. (1 ${ }^{\text {a }}$ Edição da UNESCO).

RESTREPO, Luís Carlos. O Direito à ternura. Tradução de Lúcia M. Endlich Orth. $3^{\mathrm{a}}$ ed. Petrópolis: RJ: Vozes, 2001.

SOUSA, Ana Maria Borges de. Violências: o que se esconde por entre as sinuosidades do detalhe? In: BARBOSA, Isabela Benfica; SOUSA, Ana Maria Borges de (Orgs.). Cuidar da educação, cuidar da vida. Florianópolis: UFSC, 2011.

SOUSA, Ana Maria Borges de. Infância e violência: o que a escola tem a ver com isso? 2002. 283 f. Tese (Doutorado em Educação) - Universidade Federal do Rio Grande do Sul, Porto Alegre, 2002.

SOUSA, Ana Maria Borges; MIGUEL, Denise Soares; LIMA, Patrícia de Moraes. Módulo 1: Gestão do Cuidado e Educação Biocêntrica. Florianópolis: UFSC- CED- Nuvic, 2010.

TORO, Rolando. Afectividad. Chile: International Biocentric Foundation: Escuela Modelo de Biodanza Sistema Rolando Toro, 2005.

TORO, Rolando. BIODANZA. Lineas de Vivencia. Escola de Biodanza Rolando Toro de Santa Catarina, 1998. 
A vida como referência na educação: alguns componentes do complexo fenômeno da afetividade e das violências

Sílvia Cardoso Rocha

Recebido em: 15/09/2015

Aprovado em: 29/08/2016

Universidade do Estado de Santa Catarina - UDESC

Centro de Ciências Humanas e da Educação - FAED

Revista PerCursos

Volume 17 - Número 35 - Ano 2016

revistapercursos@gmail.com 